\title{
10 ways to reconcile Social Media and 'Traditional' Education in Emergency Care
}

Published in the Emergency Medicine Journal. This is the final submitted author manuscript: http://emj.bmj.com/content/32/10/819

Dr. Damian Roland ${ }^{1,2}$

1.SAPPHIRE Group, Health Sciences, Leicester University, United Kingdom

2. Paediatric Emergency Medicine Leicester Academic (PEMLA) Group, Leicester Hospitals, Leicester, United Kingdom

E-mail: dr98@le.ac.uk

Twitter: @damian_roland

Victoria Brazil ${ }^{3}$

3. Bond University, Faculty of Health Sciences and Medicine Robina, Queensland, Australia

E-mail: victoria.brazil@gmail.com

Twitter: @socraticEM

Corresponding Author: Dr. Damian Roland

Keywords: Medical Education, Social Media

Word Count: 2325 


\begin{abstract}
Social Media has been viewed by some as a threat to traditional Medical Education. In Emergency Care the underpinning educational principles of Social Media, while sometimes innovative in their delivery, are often no different than long-standing techniques and methods. This opinion piece aims to encourage discussion and debate that reduces the divide between these two communities of practice.
\end{abstract}

\title{
What is already known on this subject?
}

Social Media is increasingly used as a platform to deliver education in Emergency and Critical Care.

There is the potential for a divide between those endorsing a traditional medical education approach and those who promote new, but potentially short lived, innovations. 


\section{Introduction}

Medical Education is an evolving discipline. Advances in healthcare delivery, changing patient demographics and shifts in workforce design necessitate frequent curricular review at undergraduate and postgraduate level - the 'what' of learning in medicine.

Effective teaching and learning also requires integration of traditional education theory with technology enhanced learning modalities - the 'how' of learning. In the last decade the explosion of new concepts (e.g. flipping the classroom [1]) and new cultures (social media) has influenced educational delivery, including health professional education.

In Emergency and Critical Care Medicine there has been a movement towards creating, curating and consuming online educational content, especially that labelled as FOAM (Free Open Access Meducation) [2,3]. This is not unique to these communities however there does appear to be a relationship between the fast paced Emergency Department environment and the 'mindset' of these specialities, with rapid and efficient educational 'transactions' in learning and education [4]. Ultimately though Social Media has provided an effective vehicle for these transactions in any clinical specialty, and offers advantages of speed and accessibility to expert opinion in an egalitarian environment. However speed and accessibility also bring challenges posting content in an unregulated and unfiltered manner has caused consternation for Social Media, especially when new and 'unproven' techniques and ideas rapidly bubble to the surface of worldwide conversations [5].

Clinical educators find themselves often caught between a rock and a hard place; a requirement to deliver a curriculum which is ever increasing in size and complexity, and a body of students and colleagues wanting to embrace new ideas appearing daily on Twitter or blog posts to drive their own learning.

There are a spectrum of views. At the extreme - battle lines have been drawn between the 'old', 'slow', 'stale', traditional approaches to medical education and the 'new', 'technology enhanced', 'anarchist' Social Media learning. This is probably neither helpful nor sustainable. We believe that reconciliation is necessary. New and old approaches to medical education and the use of social media are not competitive. Evolving learning modalities will be effective if they follow core principles of effective learning. This article describes 10 methods by which we believe this reconciliation can happen. They are based on the authors experience both as clinical educators but also as users of social media. They are not intended as didactic rules but as a framework to encourage reflection and debate. 


\section{Recognise effective use of Social Media is no different than effective use of 'traditional' medical education approaches.}

Definitions of Social Media

Social media is the social interaction among people in which they create, share or exchange information and ideas in virtual communities and networks (Wikipedia)

Social media embraces a range of technologies that allow web based and mobile applications to connect, create and engage user generated content between individuals and organisations (Prof. Simon Carley [6])

Social media is an openly accessible participation and engagement platform (Dr. Damian Roland)

Learners at all levels need a conceptual framework for their education. This should involve clarity of learning objectives, integration within a 'curriculum' (even for continuing professional development), flexibility of pace and process for learning, assessment of learning and evaluation of teaching - the core elements of any effective educational program. Present use of Social Media has strengths in Social Media of these elements but considerable gaps in others.

Effective use of social media for learning or teaching is a skill, amenable to formal instruction, practice and feedback. To date there has been limited formal guidance for either learners or teachers in developing these skills, and certainly little which is 'evidence based'. As with our clinical skills, inconsistent, individualistic approaches are unlikely to lead to best practice.

Random roaming through the blogosphere or Twitter won't lead to optimal or efficient learning, just as flipping through pages of a large anatomy text book or spend hours googling three dimensional demonstrations of the adult abdominal cavity may not either.

\section{Re-affirm the utility of the 'effective' lecture, whether you call it a podcast or not?}

Lectures offer a 'one-to-many' efficiency advantage, and structured format for content. Critics cite low learner engagement, variable relevance to learning needs and ineffectiveness. Technology enhanced ability to record and distribute material instantly means that lectures are more scrutinised, but also that they are more accessible and no 
longer require synchronous learning. A podcast is simply a lecture available for download.

Lectures and podcasts are not innately 'good' or 'bad'. Core educational principles apply

- lecturers must be prepared, have clear key points, ensure material is relevant to the learning context, utilise teaching approaches that maximise learner engagement, present material in a succinct timeframe, and receive evaluation and feedback on their performance.

Technology enhanced approaches offer opportunities within these principles - audience response systems, live streamed interviews with experts, visual aids and animation to explain concepts, but also offer distractions such as poor use of presentation software or learners ineffectively 'multi-tasking'.

The increasing use of live recordings and webexes means Social Media can raise the bar - best 'lecturing' practice becomes more visible and accessible [7-9], duplication of material can be reduced via collaborative [10] or Massive [11] open online courses, 'just in time' learning is easier (procedural skill videos) and distribution on social media can enhance debate and commentary to a wider audience.

\section{Develop and adapt your critical appraisal and EBM skills - same principles, different tools}

Learners at all levels need guidance on critically appraising research and educational content. Navigating the world of Free Open Access Meducation (FOAM) is no more or less a task than navigating an article in the Lancet. The fundamental skills of structured critique need to be embedded in all health care professions education and regularly revised irrespective of the medium to which they are applied.

We believe 'Traditional' peer review of medical research is flawed, as is pre- and postpublication, dissemination and commentary of social media content. The expert health professional learner is aware of the risks and benefits of each, and has the ability to draw upon online resources to help EBM and critical appraisal skills [12].

\section{Educate the whole health care professional and not just technical or clinical aspects.}

Continuing, and longstanding, concerns about the delivery of compassionate care by health-care professionals highlights that communication, leadership, professionalism may continue to be poorly taught compared to medical knowledge and technical skill domains in undergraduate and postgraduate curricula [13]. 
A systematic review to identify the best evidence for how professionalism in medicine should be taught [14] identified themes of role modelling and personal reflections guided by faculty as the most effective techniques.

The opportunities for social media to distribute powerful narratives about the importance of patient centred care can be synergistic with reminding medical educators to role model these attributes persistently and effectively. Enhancing the concept of a health care provider being more than the sum of their clinical knowledge is a good way to bring the positives of social media and traditional medical education together.

\section{Evaluate new methods of reflection}

Being a reflective practitioner is a vital component of personal development and professionalism. Traditional forms of reflection have been insular i.e. a healthcare professional making verbal or written notes on a particular incident and feeding back to a sole supervisor or mentor. Social media has empowered very personal but public facing reflection. This has advantages in that key learning may be shared and perhaps, more importantly, common themes identified by those who having seen others acknowledge particular issues are now willing to do so themselves.

However this open reflection may leave practitioners vulnerable to a wide audience, or potentially in breach of confidentiality.

The use of blogs as a personal reflective tool is not new but the growing development of online communities means the sharing of this information is now happening at pace. The noticing, processing and Future action questions that facilitate refection [15] are prompted by the rapid natures of blog sharing and commenting. Other mediums also exist in which reflection plays a significant role; for example twitter may be used to make short reflective statements in real time and through conferences like SMACC (Social Media and Critical Care) [8] public orientated lectures with an expert reflecting on their practice are becoming more common. In our opinion medical educators must be comfortable with supporting reflection via all these methods but also be aware of personal safety and confidentiality of patients. .

\section{Use Social Media as a medium, not a curriculum}

Social media is used to create, filter/ 'curate' and disseminate educational material but it is not a curriculum, which should be specific to a learner group and their context. However the information available via social media can easily be used to populate curricula. Recently the College of Emergency Medicine (UK) and Australasian College 
for Emergency Medicine (ACEM) have made efforts to incorporate FOAM that links to their own curricula $[16,17]$

Social Media curricular domains will require direct clinical contact or face to face learning, and be less easily satisfied with social media. Without the need to articulate explicit learning objectives, material on social media may lack a clear objective, although conversely, 'grey' areas in curricula may be well filled by unique educational content on social media.

Those with educational leadership responsibilities should undertake mapping exercises to determine gaps in delivery of curricular content, whether through 'traditional' delivery or social media. Awareness of quality FOAMed resources will assist this process. Online 'conversations' relating to contemporary healthcare practice and challenges to accepted wisdom should also inform curricular evolution over time.

\section{Remain professional - same principles, different medium}

Social media has put a spotlight on unprofessional behaviour with a number of public cases of health care professionals undertaking behaviours not in keeping with their status. However, poor professionalism is not new, even if social media hastens and extends its visibility. Both traditional medical education and social media communities should reaffirm the importance of professionalism and positive healthcare cultures.

Medical schools and professional associations have developed and disseminated resources to assist Social Media users in this regard, and most institutions have developed policies on social media use[18]. The General Medical Council of the United Kingdom [19] has produced clear guidance on the use of social media for doctors which highlights the following point

"The standards expected of doctors do not change because they are communicating through social media rather than face to face or through other traditional media. However, using social media creates new circumstances in which the established principles apply."

We believe a balance needs to be maintained between 'upholding standards' and 'stifling innovation/ censoring'. Again this tension is not new - mainstream media has been navigating these grey zones since radio and television first appeared. 


\section{Use Social Media for faculty development}

Teachers in healthcare and in other disciplines need preparation and training for their educational role. Many resources for educators exist on social media, and there are blogs and podcasts with faculty development as the primary focus e.g. iteachEM (iteachEM.net) and KeyLime (http://keylimepodcast.royalcollege.ca).

A systematic review of faculty development initiatives in medical education found key features associated with improved teaching effectiveness - use of experiential learning, provision of feedback, effective peer and colleague relationships, interventions following principles of teaching and learning, and the use of a diversity of educational methods [20]. Integration of these principles within Social Media faculty development initiatives is under developed. Experiential learning and peer feedback could be enhanced through technology enabled peer observation of teaching. Building communities of educators through various Social Media platforms is a key step to collaboration and sharing expertise. As previously described, the resources available need to be 'pulled' into a carefully planned faculty development plan specific to healthcare educators role. Conversely, 'traditional' faculty development initiatives may not include social media knowledge and skills as part of the educator's tool kit. Social Media enthusiasts need to influence this community to assist development of teaching skills appropriate for the current generation of healthcare learners.

\section{Enhance opportunities for assessment and feedback via Social Media}

Assessment and feedback is important for ensuring learning has occurred, and for maintenance of competency standards within healthcare professions. Assessment processes need to be valid, reliable, acceptable, feasible and have educational effect i.e. drive learning [21]. There have been significant changes in assessment practice in undergraduate and postgraduate medical training, include a greater variety of methods, programmatic approaches and use of workplace based assessments.

We observe that social media has currently had a very limited role in assessment in health professional education, and to many that role may appear 'counter culture' to the FOAM experience, and more appropriately the province of 'traditional' institutions. However there are a number FOAM resources specifically devoted to examination preparation (http://lifeinthefastlane.com/exams/ or http://www.edexam.com.au/) and the online platform has enabled widespread accessibility and collaboration for these resources. 
Further opportunities exist, including using crowdsourcing for assessment, as demonstrated by Peter Norvig's Stanford University MOOC [22] which involved over 150,000 learners, or online assessment and feedback of procedural skills in distributed educational settings [23].

Using Twitter for supervision of medical learners has been described; 'Supertwision' [24] which offer opportunities, albeit within limits of patient and learner privacy and confidentiality.

\section{Embrace Social Media as a method of dissemination of scholarly work}

The dissemination of scholarly activity can be a challenge. Social media may be considered a helpful adjunct to more traditional mechanisms although there are risks in assuming reach (or lack thereof) is synonymous with impact [25].

Social Media educators and researchers should adhere to principles of quality academic output. A short blog is not a substitute for a careful considered review article - although both may have their use in the 21st century. Peer review processes can be enhanced by the reach of social media [26] either formally or informally via posts on blogs or websites.

Many 'traditional' journals are also modifying their formats and publication processes to more collaborative and Social Media approaches - multimedia offerings, and alerts via Twitter and RSS feeds. Social Media blog posts and podcasts offer a greater speed of dissemination and discussion following the release of new research than previously possible, through connected online professional communities [27].

\section{Conclusion}

We believe that reconciling traditional with Social Media based Medical Education is not difficult - effective approaches in either medium are based on classic educational theory and principles. Social Media offers opportunities to enhance learning that were previously not available, but the principles are not new.

Finally, the distinction between these approaches is fast becoming a false dichotomy. Best practice in health care education now demands a hybridization approach - in which media should be selected for their utility in achieving whichever learning outcomes are required. 
Competing Interests: No competing interests are declared

Acknowledgments: Nil

Funding: No funding was required or utilised

Contributorship: Dr. Damian Roland and Dr. Victoria Brazil equally contributed to the writing of draft and final versions of this manuscript

\section{References}

1. Prober CG, Khan S. Medical education reimagined: A call to action. Acad Med.

2013;88:1407-1410

2. Nickson CP, Cadogan MD. Free Open Access Medical education (FOAM) for the emergency physician Emergency Medicine Australasia 2014; 26(1):76-83

3. Cadogan M, Thoma B, Chan TM et al. Free Open Access Meducation (FOAM): the rise of emergency medicine and critical care blogs and podcasts (2002-2013). Emerg Med J. $2014 \mathrm{Feb}$ 19. doi: 10.1136/emermed-2013-203502. [Epub ahead of print] PMID: 24554447.

4. Lin. M. Why emergency medicine is the leader in social media and medical education http://icenetblog.royalcollege.ca/2014/06/20/why-is-emergency-medicine-the-leader-in-socialmedia-and-medical-education/ (website last accessed 7th July 2015)

5. Lex J and Genes N PRO/CON: Why \#FOAMed is Essential to EM Education Joe Lex and Nicholas Genes Emeregncy Physiciaons Months April 2014

http://www.epmonthly.com/features/current-features/pro-con-is-foam-essential-to-em-educationyes/ (website last accessed 7th July 2015)

6. Roland D, May N, Body R, Carley S and Lyttle M. Are you a SCEPTIC? SoCial mEdia Precision \& uTility In Conferences Emerg Med J 2015;32:412-413

7. Ted Talks http://www.ted.com/talks Website last accessed 7th July 2015

8. SMACC Gold http://www.smacc.net.au/the-talks/ Website last accessed 7th July 2015

9, Khan Academy https://www.khanacademy.org Website last accessed \&th July2015

10. Wiecha $\mathrm{J}$ and Barrie N. Collaborative online learning: A new approach to distance CME Acad Med. 2002 Sep;77(9):928-9. 
11. McNutt M. Bricks and MOOCs Science. 2013 Oct 25;342(6157):402

12. Carley S. Bestbets Checklists for critical appraisal. http://stemlynsblog.org/jc-bestbetschecklists-critical-appraisal-st-emlyns/ (webstie last accessed $10^{\text {th }}$ May 2015)

13. Burack J, Irby D, Carline J, at al. Teaching compassion and respect: Attending physicians responses to problematic behaviours J Gen Intern Med. Jan 1999; 14(1): 49-55.

14. Birden H1, Glass N, Wilson I, at al. Teaching professionalism in medical education: a Best Evidence Medical Education (BEME) systematic review. BEME Guide No. 25 Med Teach. 2013 Jul;35(7):e1252-66

15. Menard L and Ratnaplan S. Reflection in Medicine Can Fam Physician. Jan 2013; 59(1): 105-107.

16. College of Emergency Medicine (UK) FOAMed network http://www.cemfoamed.co.uk Website last accessed $7^{\text {th }}$ July 2015

17. Best of Web EM. Australasian College of Emergency Medicine https://www.acem.org.au/About-ACEM/Programs-Projects/Best-of-Web-EM.aspx Website last accessed 10th May 2015

18 Social Media Policy Database. Social mediagovernance.com Website last accessed $7^{\text {th }}$ July 2015

19. Doctors use of Social Media. General Medical Council 2013 http://www.gmcuk.org/guidance/ethical guidance/21186.asp Website last accessed 7th July 2015

20. Steinert Y, Mann K, Centeno A, at al. A systematic review of faculty development initiatives designed to improve teaching effectiveness in medical education: BEME Guide No. 8. Med Teach. 2006 Sep;28(6):497-526.

21. CVan der Vleuten C.P.M, Schuwirth L.W. Assessing professional competence: From methods to programmes. Medical Education 2005 39;3: 309-317)

22. The 100000 student classroom

http://www.ted.com/talks/peter_norvig_the_100_000_student_classroom?language=en

Website last accessed $10^{\text {th }}$ May 2015

23. Engstrom, C. et al. eCAPS-An innovative web-based online system for clinical assessment of practical skills in joint examination. Journal of Science and Medicine in Sport, Volume 14 , e63 - e64

24. AMS Doctor. Supertwision http://amsdr.blogspot.com.au/2013/01/supertwision-join-newexperiment-in.html Website last accessed 7th July y 2015 
25. Fox CS, Bonaca MP, Ryan JJ, et al. A Randomized Trial of Social Media from Circulation Circulation 2014 Published online before print doi:10.1161/CIRCULATIONAHA.114.013509

26. Introducing Open Post Publication Peer Review. Academic Life in Emergency Medicine. http://www.aliem.com/introducing-open-post-publication-peer-review/ Website last accessed $7^{\text {th }}$ July 2015

27. Research and Reviews. Life in the Fast Lane http://lifeinthefastlane.com/education/research-and-reviews/ Website Last Accessed $7^{\text {th }}$ July2015 